\title{
RELEVANSI NILAI INFORMASI AKUNTANSI: STUDI PERBANDINGAN ANTARA PERUS- AHAAN BUMN DAN PERUSAHAAN NON-BUMN YANG TERDAFTAR DI BURSA EFEK IN- DONESIA
}

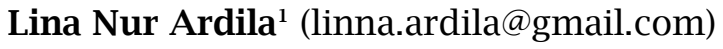

Doddy Setiawan'1 (doddy.setiawan@gmail.com)

${ }^{1}$ Program Studi Magister Akuntansi, Fakultas Ekonomi dan Bisnis, Universitas Sebelas Maret, Indonesia

\author{
ABSTRACT
}

This study compares value relevance of accounting information of state-owned companies (BUMN Persero Terbuka) and that of non-state-owned companies, especially state-owned companies listed on the Indonesia Stock Exchange (IDX). The accounting information examined in this study includes earnings per share (EPS) and book equity value per share (BVPS). This study uses an unbalanced panel data sample that includes 97 state-owned companies and 97 non-state-owned companies. By using multiple regression analysis, the results of this study indicate that the value relevance of EPS (or the effect of EPS on stock prices) and the value relevance of the book equity value per share (BVPS) of state-owned companies is not different from the value relevance EPS and BVPS of non-state-owned companies, after controlling for sustainability reporting award (SRA), debt financing (DAR), company size. The implication of the findings of this research is that state-owned companies (BUMN Persero Terbuka) need to improve the quality of accounting information especially EPS and BVPS in order to compete with non-non-state-owned companies.

Keywords: Value relevance of financial statements, earnings per share (EPS), book value per share (BVPS), state-owned companies (BUMN), non- state-owned companies (non-BUMN).

Penelitian ini membandingkan antara relevansi nilai informasi akuntansi perusahaan Badan Usaha Milik Negara (BUMN) khususnya BUMN Persero Terbuka dan perusahaan non-BUMN yang terdaftar di Bursa Efek Indonesia. Informasi akuntansi yang diuji dalam penelitian ini mencakup laba per saham (earnings per share, EPS) dan nilai buku ekuitas per saham (book-value per share, BVPS). Penelitian ini menggunakan menggunakan sampel data panel (unbalanced) yang meliputi 97 perusahaan BUMN dan 97 perusahaan NON-BUMN dalam periode 2014-2016. Dengan menggunakan analisis regresi berganda, hasil penelitian ini menunjukkan bahwa relevansi nilai EPS (atau pengaruh EPS terhadap harga saham) dan relevansi nilai dari nilai buku ekuitas per saham (BVPS) perusahaan-perusahaan BUMN adalah tidak berbeda dibandingkan dengan relevansi nilai EPS perusahaan non-BUMN. Hasilhasil tersebut sudah mempertimbangkan penggunaan variabel kontrol sustainability reporting award (SRA), penggunaan utang (DER), dan ukuran perusahan (SIZE). Implikasi temuan penelitian ini adalah bahwa perusahan-perusahaan BUMN perlu meningkatkan kualitas informasi dalam laporan keuangan khususnya EPS, dan BVPS agar mampu bersaing dengan perusahaan-perusahaan non-BUMN.

Kata Kunci: relevansi nilai laporan keuangan, laba per saham (earnings per share, EPS), nilai buku per saham (book value per share, BVPS), perusahaan Badan Usaha Milik Negara (BUMN), perusahaan non Badan Usaha Milik Negara (NON-BUMN).

\section{PENDAHULUAN}

Dalam melakukan keputusan investasi saham di pasar modal, investor terlebih dulu menentukan nilai intrinsik saham (atau nilai berdasarkan analisis investor yang bersangkutan) yang digunakan sebagai dasar untuk pengambilan keputusan investasi. Keputusan investasi yang dilakukan investor dapat berupa membeli saham jika harga saham yang ditawarkan di pasar modal lebih rendah dari nilai intrinsik, atau tidak membeli saham jika harga saham yang ditawarkan di pasar modal lebih tinggi dari nilai intrinsik, atau menjual saham yang telah dimilikinya jika harga saham yang diminta di pasar modal lebih tinggi 
dari nilai intrinsik, atau tidak menjual saham yang telah dimilikinya jika harga saham yang diminta di pasar modal lebih rendah dari nilai intrinsik. Hasil keputusan investasi tercermin pada harga saham yang terjadi di pasar modal.

Laporan keuangan dimaksudkan agar berguna dalam pengambilan keputusan intestasi. Jika informasi dalam laporan keuangan berguna bagi investor, maka informasi tersebut berpengaruh terhadap harga saham. Oleh sebab itu, banyak studi telah dilakukan untuk meneliti kemanfaatan informasi akuntansi termasuk laporan keuangan dengan menguji relevansi nilai informasi akuntansi, yang antara lain dilakukan dengan menguji keterkaitan antara informasi akuntansi dan harga saham atau return saham.

Perusahaan yang terdaftar di Bursa Efek Indonesia (BEI) dapat dikelompokkan menjadi 2 (dua) perusahaan Badan Usaha Milik Negara (BUMN) dan perusahaan nonBUMN. BUMN yang menjual saham di pasar modal disebut perusahaan perseroan terbatas terbuka (PT Persero Tbk.). Perusahaan BUMN Persero mempunyai tujuan utama mengejar keuntungan (UU No. 19 Tahun 2003 tentang BUMN). Dalam rangka mencapai tujuan tersebut perusahaan BUMN harus bersaing dengan perusahaan non-BUMN. Keuntungan yang dicapai oleh BUMN tercermin dalam laporan keuangan khususnya dalam laporan laba rugi.

BUMN mengemban misi negara khususnya dalam memberi kontribusi finansial kepada negara. Dalam menjalankan misi tersebut, BUMN yang go-public harus mampu bersaing dengan Non-BUMN. Penelitian ini menguji kemampuan bersaing BUMN dengan NON-BUMN dalam hal penyajian kualitas informasi akuntansi. Penelitianpenelitian sebelumnya belum menguji hal tersebut. Studi ini bertujuan untuk mendapatkan bukti empiris tentang hal tersebut.

Penelitian-penelitian sebelumnya tentang BUMN telah dilakukan di Indonesia dengan berbagai pendekatan. Beberapa studi seperti Cahyaningrum (2009), Kusumadewi (2013), Marina et al. (2013), merupakan studi deskriptif kualitatif exploratif atau deskriptif kuantitatif. Bebera- pa studi sebelumnya yang lain seperti Fitriani (2013), Istighfarin dan Wirawati (2015), Avianti (2017), Ciptaningsih (2013), Suharli dan Nurlaelah (2008), Agustina et al. (2015), dan Rahmawati et al. (2014) merupakan studi kausalitas (menguji pengaruh variabel independen pada variabel dependen) yang menggunakan variabelvariabel akuntansi saja tanpa menggunakan variabel-variabel pasar (seperti return saham, nilai saham). Di samping itu, studi-studi sebelumnya yang lain membandingkan perusahaan BUMN dan non-BUMN dengan menggunakan variabel-variabel akuntansi dan/atau variabel pasar (seperti return saham atau nilai saham) misalnya rasio-rasio keuangan dan nilai perusahaan (Lebelaha, 2016), rasio keuangan dan return saham (Thrisye dan Nicodemus Simu, 2013). Penelitianpenelitian tersebut tidak membandingkan relevansi informasi akuntansi perusahaan BUMN dan NON-BUMN.

Sebuah studi di Cina (Liu, 2014) melakukan perbandingan antara relevansi nilai informasi dalam laporan keuangan untuk perusahaan-perusahaan yang standar akuntansi lokal dan relevansi nilai informasi dalam laporan keuangan untuk perusahaan-perusahaan yang standar akuntansi internasional, IFRS. Mengikuti Liu (2014) tersebut, penelitian yang dilakukan ini membandingkan relevansi nilai informasi laporan keuangan perusahaan BUMN dan relevansi nilai informasi laporan keuangan perusahaan non-BUMN. Perbedaan studi ini dengan studi Liu adalah bahwa Liu menggunakan perbedaan standar akuntansi yang digunakan (standar akuntansi lokal versus standar akuntansi internasional, IFRS) sebagai dasar pembandingan, sedangkan studi ini menggunakan jenis perusahaan (BUMN versus NON-BUMN) sebagai dasar pembandingan. Hasil penelitian ini diharapkan memberi kontribusi dengan menyediakan hasil empiris tentang perbandingan tersebut.

Perbandingan relevansi nilai BUMN dengan NON-BUMN dilakukan untuk mengetahui relevansi nilai BUMN secara relatif (perlu pembanding) yaitu dibandingkan dengan NON-BUMN dalam industri 
yang sejenis. Informasi akuntansi BUMN mungkin sudah mempunyai relevansi tetapi bisa lebih tinggi, atau lebih rendah, atau sama dengan relevansi nilai informasi akuntansi NON-BUMN.

Berdasarkan latar belakang sebagaimana diuraikan di atas, masalah penelitian ini dirumuskan sebagai berikut:

(1) Apakah terdapat relevansi nilai informasi dalam laporan keuangan perusahaan BUMN? Pertanyaan penelitian ini dirinci menjadi 2 (dua) sebagai berikut:

(a) Apakah laba per saham (earnings per share, EPS) perusahaan BUMN berpengaruh positif terhadap harga saham?

(b) Apakah nilai buku ekuitas per saham (book value per share, BVPS) perusahaan BUMN berpengaruh positif terhadap harga saham?

(2) Apakah terdapat relevansi nilai informasi dalam laporan keuangan perusahaan NON-BUMN? Pertanyaan penelitian ini juga dirinci menjadi 2 (dua) sebagai berikut:

(a) Apakah laba per saham (earnings per share, EPS) perusahaan NON-BUMN berpengaruh positif terhadap harga saham?

(b) Apakah nilai buku ekuitas per saham (book value per share, BVPS) perusahaan NON-BUMN berpengaruh positif terhadap harga saham?

(3) Apakah relevansi nilai informasi dalam laporan keuangan perusahaan BUMN lebih tinggi dibandingkan dengan relevansi nilai informasi dalam laporan keuangan perusahaan NON-BUMN? Pertanyaan penelitian ini juga dirinci menjadi 2 (dua) sebagai berikut:

(a) Apakah relevansi nilai informasi laba per saham (EPS) BUMN lebih tinggi dibandingkan dengan relevansi nilai informasi laba per saham (EPS) NON-BUMN?

(b) Apakah relevansi nilai informasi nilai buku ekuitas per saham (BVPS) BUMN lebih tinggi dibandingkan dengan relevansi nilai informasi nilai buku ekuitas per saham (BVPS) NON-BUMN?

Sistematika artikel pada bagian- bagian berikut ini meliputi tinjauan pustaka dan pengembangan hipotesis yang diikuti dengan metode penelitian dan hasil empiris, dan diakhiri dengan simpulan, keterbatasan, serta saran untuk penelitian selanjutnya.

\section{TINJAUAN PUSTAKA DAN PENGEM- BANGAN HIPOTESIS}

Dewan Standar Akuntansi Keuangan Ikatan Akuntan Indonesia (DSAK IAI) telah mengesahkan Exposure Draft Kerangka Konseptual Pelaporan Keuangan (ED KKPK) menjadi Kerangka Konseptual Pelaporan Keuangan (KKPK) dalam rapatnya pada tanggal 28 September 2016. KKPK merupakan adopsi dari the Conceptual Framework for Financial Reporting per 1 Januari 2016. KKPK ini akan menggantikan Kerangka Dasar Penyusunan dan Penyajian Laporan Keuangan (KDPPLK) (Penyesuaian 2014) yang berlaku efektif per 1 Januari 2015. KKPK berlaku efektif sejak tanggal pengesahan.

Berdasarkan rerangka konseptual, tujuan pelaporan keuangan adalah menyediakan informasi yang berguna bagi pengguna terutama investor dan kreditor dalam pengambilan keputusan investasi. Studi tentang kemanfaatan informasi keuangan untuk keputusan investasi sering menggunakan istilah studi tentang relevansi nilai informasi akuntansi, karena informasi akuntansi tersebut relevan dalam menentukan nilai intrinsik sekuritas/ saham dan selanjutnya digunakan untuk keputusan investasi yang tercermin dalam harga pasar saham.

Informasi keuangan memiliki karakteristik kualitatif fundamental yaitu relevan dan representasi tepat. Suatu informasi harus mampu memberikan gambaran kepada pengguna untuk menentukan nilai instrinsik perusahaan dengan baik. Dapat disimpulkan bahwa kualitas kinerja tercermin dari angka-angka yang tersaji pada laporan keuangan dan menggambarkan keadaan keuangan perusahaan. Laporan keuangan merupakan suatu alat komunikasi secara tidak langsung yang menghubungkan antara perusahaan dan investor. Jadi agar informasi tersebut menjadi efektif harus dapat menjadi dasar per- 
spektif penggunanya dalam menganalisis risiko maupun memprediksi tingkat return dan menentukan keputusan dalam berinvestasi.

Pada dasarnya konsep relevansi nilai berkaitan dengan konsep kegunaan keputusan pada suatu informasi akuntansi. Sebagaimana tujuan laporan keuangan harus memiliki nilai relevan, jika informasi akuntansi yang disajikan dapat mempengaruhi perbedaan keputusan investor maupun kreditor. Artinya isi informasi akuntansi yang disajikan pada laporan keuangan perusahaan telah menjadi isu yang menarik (penting) bagi pengguna, sehingga reaksi tersebut dapat membuktikan bahwa informasi bermanfaat. Informasi yang relevan memiliki nilai umpan balik bagi penggunanya, sehingga diharapkan dapat membantu membuat penilaian baru atas informasi yang tersedia dan dengan membandingkan/ mengoreksi ekspektasi masa lalu.

\section{Badan Usaha Milik Negara (BUMN)}

Badan Usaha Milik Negara (BUMN) adalah badan usaha yang seluruh atau sebagian besar modalnya dimiliki oleh negara melalui penyertaan secara langsung yang berasal dari kekayaan negara yang dipisahkan (UU No. 19 Tahun 2003 tentang Badan Usaha Milik Negara Pasal 1 angka 1). BUMN terdiri dari Perusahaan Perseroan (Persero) dan Perusahaan Umum (Perum) (UU No. 19 Tahun 2003 Pasal 9 angka 2-4). Sedangkan non-BUMN atau yang disebut dengan badan usaha milik swasta (NON-BUMN) merupakan badan usaha yang dibangun dan dirintis oleh satu pengusaha atau sekelompok pengusaha. Pemerintah telah mengatur NON-BUMN diantaranya adalah tidak boleh menguasai sumber daya alam yang sangat penting yang menjadi kepentingan hajat orang banyak (UUD 1945).

Perusahaan Perseroan (Persero) adalah BUMN yang berbentuk perseroan terbatas yang modalnya terbagi dalam saham yang seluruh atau paling sedikit $51 \%$ (lima puluh satu persen) sahamnya dimiliki oleh Negara Republik Indonesia yang tujuan utamanya mengejar keuntungan. Fokus penelitian ini adalah BUMN Persero Terbuka yaitu Persero yang modal dan jumlah pemegang sahamnya memenuhi kriteria tertentu atau Persero yang melakukan penawaran umum sesuai dengan peraturan perundang-undangan di bidang pasar modal. (Pasal 9 angka 3 UU No. 19 Tahun 2003). Untuk mencapai tujuan utama mengerjar keuntungan, BUMN Persero Terbuka harus bersaing dengan perusahaan-perusahaan swasta (non-BUMN).

\section{Penelitian tentang BUMN}

Penelitian-penelitian sebelumnya tentang BUMN telah dilakukan di Indonesia dengan berbagai pendekatan. Beberapa studi merupakan studi deskriptif yang bersifat deskriptif kualitatif exploratif atau deskriptif kuantitatif. Temuan penelitianpenelitian tersebut antara lain sebagai berikut. Terdapat hambatan implementasi tata kelola perusahaan yang baik (good corporate governance) pada badan usaha milik negara (BUMN) yang berbentuk Persero (Cahyaningrum, 2009); Corporate social responsibility (CSR) PT. TELKOM Kandatel Malang melalui Program Kemitraan termasuk kedalam Kelompok hijau dengan menggunakan model kemitraan mutualistik dan menerapkan pola kemitraan inti plasma (Kusumadewi, 2013). Diusulkan pembentukan bank syariah dengan mengubah PT Bank BRI Tbk menjadi syariah dan diikuti oleh akuisi tiga bank syariah milik negara lainnya sehingga bank syariah baru (bank syariah) berpotensi menjadi bank Islam terbesar di dunia (Marina et al., 2013); Dari keempat perbankan BUMN (BNI, BRI, BTN, dan Bank Mandiri), kinerja keuangan paling baik dimiliki BRI yaitu Return on Asset paling besar tahun 2010-2012, sedangkan kinerja keuangan paling lemah dimiliki BTN dengan diperolehnya LDR di bawah standar BI untuk predikat sehat (Kaligis, 2013).

Beberapa studi sebelumnya merupakan studi kausalitas (menguji pengaruh variabel independen pada variabel dependen) yang menggunakan variabelvariabel akuntansi tetapi tidak menggunakan variabel-variabel pasar (seperti return saham, nilai saham). Temuan dari penelitian-penelitian tersebut antara lain sebagai berikut. Environmental 
performance berpengaruh positif pada financial performance, sedangkan environmental cost tidak (Fitriani, 2013). Kepemilikan institusional dan CGPI berpengaruh positif signifikan terhadap profitabilitas, sedangkan ukuran dewan komisaris independen dan komite audit tidak berpengaruh signifikan terhadap profitabilitas (Istighfarin and Wirawati, 2015). Privatisasi BUMN (kepemilikan publik) dan penegakan good corporate governance (peran komite audit dan direktur/komisaris independen) berpengaruh pada kinerja (Avianti, 2017). VAIC tidak memiliki pengaruh terhadap kinerja keuangan perusahaan, HCE tidak berpengaruh terhadap kinerja keuangan perusahaan, SCE berpengaruh positif terhadap kineja perusahaan, CEE berpengaruh positif terhadap kinerja keuangan perusahaan, VAIC tahun lalu tidak berpengaruh terhadap kinerja keuangan perusahaan saat ini, HCE tahun lalu tidak berpengaruh terhadap kinerja keuangan perusahaan saat ini, SCE tahun lalu tidak berpengaruh terhadap kinerja keuangan perusahaan saat ini, dan CEE tahun lalu berpengaruh positif terhadap kinerja keuangan perusahaan saat ini (Ciptaningsih, 2013). Rasio konsentrasi dan ukuran auditee perusahaan berpengaruh pada audit fee, sedangkan ukuran KAP dan jumlah anak perusahaan tidak (Suharli dan Nurlaelah, 2008). Intelectual capital, corporate social responsibility dan good corporate governance berpengaruh terhadap kinerja keuangan perusahaan. (Agustina et al., 2015). Kinerja keuangan (TATO, NPM, dan DER) berpengaruh pada kebijakan dividen, sedangkan ROI tidak (Rahmawati et al. 2014).

Beberapa studi sebelumnya yang lain membandingkan perusahaan BUMN dan non-BUMN dengan menggunakan variabelvariabel akuntansi dan/atau variabel pasar (seperti return saham atau nilai saham). Temuan penelitian-penelitian tersebut antara lain sebagai berikut. Price earnings ratio berpengaruh terhadap nilai perusahaan, sedangkan debt to equity ratio dan dividend payout ratio tidak berpengaruh terhadap nilai perusahaan (Lebelaha, 2016). Rasio keuangan CR,TATO, dan ROA tidak berpengaruh positif pada return saham, sedangkan DER berpengaruh negatif pada return saham. (Thrisye dan Nicodemus Simu, 2013).

Lebelaha (2016) menguji dan menemukan bahwa price earnings ratio berpengaruh terhadap nilai perusahaan (BUMN), sedangkan debt to equity ratio dan dividend payout ratio tidak berpengaruh terhadap nilai perusahaan. Asyikin \& Tanu (2016) menemukan bahwa kinerja keuangan antara perusahaan farmasi milik swasta yang terdaftar di Bursa Efek Indonesia lebih baik dibandingkan dengan kinerja keuangan BUMN yang terdaftar di Bursa Efek Indonesia. Liu (2014) menguji perbedaan antara perusahaan yang diperdagangkan (saham A) untuk investor domestik (menggunakan standar akuntansi lokal) dan relevansi nilai laporan keuangan pada perusahaan yang diperdagangkan (saham B) untuk investor asing (menggunakan IFRS). Hasilnya menunjukkan bahwa relevansi nilai laporan keuangan yang berbasis IFRS lebih tinggi dibandingkan dengan relevansi nilai laporan keuangan yang menggunakan standar akuntansi lokal.

\section{Pengembangan Hipotesis}

Penelitian ini menguji relevansi nilai informasi dalam laporan keuangan yang meliputi laba per saham (earnings per share, EPS) dan nilai buku ekuitas per saham (book value per share, BVPS). Relevansi nilai laba (value relevance of earnings) menunjukkan relevansi (pentingnya) informasi laba akuntansi bagi investor dalam menilai saham (Dechow dan Ge, 2006), dan relevansi nilai merupakan reaksi pasar atas informasi laba (Scott, 2015). Relevansi nilai informasi akuntansi ditunjukkan oleh pengaruh positif informasi akuntansi terhadap harga saham. Dalam studi ini sebagaimana dikemukakan di atas, informasi akuntansi yang diuji meliputi EPS dan BVPS.

Informasi akuntansi dalam laporan keuangan berpengaruh positif terhadap harga saham karena laporan keuangan disusun berdasarkan standar akuntansi dan standar akuntansi ini disusun berdasarkan kerangka konseptual pelaporan keuangan yang memuat komponenkomponen konsep pelaporan keuangan tujuan laporan keuangan, karakteristik 
kualitatif informasi, pengukuraan dan pengakuan, dan elemen-elemen laporan keuangan. Tujuan laporan keuangan adalah menyediakan informasi yang bermanfaat bagi pengguna (terutama investor dan kreditor) dalam pengambilan keputusan investasi. Pendekatan tersebut dinamakan decision usefulness approach to financial reporting (Scott, 2015). Pendekatan ini mendasarkan pada teori-teori yang sudah ada seperti teori keputusan (dicision theory) dan teori pasar efisien dalam bentuk setengah kuat (semi-strong form of efficient securities market theory) (Scott, 2015).

Banyak studi sebelumnya seperti Linda \& Ningsih (2012), Aryati \& Wibowo, (2017), Yudiman \& Ahmar (2017), Aryadi et al. (2018) menguji apakah informasi akuntansi mempunyai nilai relevansi atau informasi akuntansi berpengaruh terhadap harga saham atau return saham. Linda \& Ningsih (2012) dan Aryati \& Wibowo, (2017) menemukan bahwa laba mempunyai relevansi nilai (laba berpengaruh positif terhadap harga/return saham), sedangkan Yudiman \& Ahmar (2017) menemukan bahwa laba tidak berpengaruh terhadap return saham (laba tidak mempunyai relevansi nilai), dan Aryadi et al. (2018) menemukan bahwa laba berpengaruh negatif terhadap return saham Linda \& Ningsih (2012) menggunakan sampel perusahaan dari berbagai industri, Aryati \& Wibowo (2017) dan Yudiman \& Ahmar (2017) menggunakan sampel perusahaan manufaktur, dan Aryadi et al. (2018) menggunakan sampel perusahaan jasa keuangan. Penelitian-penelitian tersebut tidak memisahkan antara perusahaan BUMN dan Non-BUMN. Penelitian ini menguji relevansi nilai informasi akuntansi perusahaanperusahaan BUMN dan perusahaanperusahaan NON-BUMN. Sesuai dengan konsep kegunaan informasi akuntansi, informasi akuntansi dalam laporan keuangan perusahaan-perusahaan BUMN atau perusahaan-perusahaan NON-BUMN diduga mempunai relevansi nilai. Karena relevansi nilai informasi ditunjukkan oleh pengaruh informasi akuntansi terhadap harga saham dan studi ini menguji 2 (dua) jenis informasi akuntansi yang meliputi laba per saham (earning per share, EPS) dan nilai buku ekuitas per saham (book value per share, BVPS) maka hipotesis-hipotesis relevansi nilai informasi akuntansi dirinci menjadi dua hipotesis sesuai jenis informasi yang diuji. Oleh sebab itu, dirumuskan hipotesishipotesis relevansi informasi akuntansi dalam laporan keuangan perusahaanperusahaan BUMN (hipotesis 1) dan perusahaan-perusahaan NON-BUMN (hipotesis 2) sebagai berikut:

H1: Terdapat relevansi nilai informasi dalam laporan keuangan perusahaan -perusahaan BUMN.

H1a: Laba per saham (earning per share, EPS) perusahaan-perusahaan BUMN berpengaruh positif terhadap harga saham.

H1b: Nilai buku ekuitas per saham (book value per share, BVPS) perusahaanperusahaan BUMN berpengaruh positif terhadap harga saham.

H2: Terdapat relevansi nilai informasi dalam laporan keuangan perusahaan -perusahaan NON-BUMN.

H2a: Laba per saham (earning per share, EPS) perusahaan-perusahaan NONBUMN berpengaruh positif terhadap harga saham.

H2b: Nilai buku ekuitas per saham (book value per share, BVPS) perusahaanperusahaan NON-BUMN berpengaruh positif terhadap harga saham.

Beberapa studi sebelumnya menemukan bahwa relevansi informasi akuntansi dipengaruhi oleh faktor tertentu seperti konservatisme akuntansi (Alexander \& Meiden, (2017), mekanisme tata kelola perusahaan (Chasanan \& Kiswara, 2017), manajemen laba (Rahman, 2017), perubahan laba atau dummy net income, DNI (Umbara et al., 2017), adopsi IFRS (Romadhoni \& Purwanti, 2018), pemenang atau non-pemenang sustainability reporting award (SRA) (Sutopo et al., 2018). Dalam penelitian ini jenis perusahaan dikelompokkan menjadi dua (perusahaanperusahaan BUMN dan perusahaanperusahaan NON-BUMN). Jenis perusahan ini diduga dapat mempengaruhi relevansi informasi akuntansi. Perusahaan BUMN khususnya yang berbentuk perseroan terbatas (Persero) dimaksudkan untuk menghasilkan keuntungan agar dapat 
memberi kontribusi keuangan kepada negara. Perusahaan BUMN Persero terbuka (BUMN yang menjual sahamnya di bursa efek (di Indonesia Bursa Efek Indonesia, BEI) harus bersaing dengan perusahaanperusahaan non-BUMN. Oleh sebab itu, perusahaan-perusahaan BUMN Persero terbuka tersebut seharusnya dapat lebih unggul dibandingkan dengan perusahaanperusahaan non-BUMN. Salah satu ukuran keunggulan tersebut adalah kualitas informasi keuangan yang dihasilkan atau relevansi nilai dari informasi keuangan yang dihasilkan. Oleh sebab itu, hipotesis perbandingan antara relevansi nilai informasi laporan keuangan perusahaan-perusahaan BUMN dan perusahaan-perusahaan NONBUMN dirumuskan sebagai berkut.

H3: Relevansi nilai informasi dalam laporan keuangan untuk perusahaanperusahaan BUMN lebih tinggi dibandingkan dengan relevansi nilai informasi dalam laporan keuangan untuk perusahaan-perusahaan NonBUMN.

H3a: Relevansi nilai EPS untuk perusahaan -perusahaan BUMN lebih tinggi dibandingkan dengan relevansi nilai EPS untuk perusahaan-perusahaan NON-BUMN.

H3b: Relevansi nilai BVPS untuk perusahaan-perusahaan BUMN lebih tinggi dibandingkan dengan relevansi nilai BVPS untuk perusahaan-perusahaan NON-BUMN.

\section{METODE PENELITIAN}

Penelitian ini menggunakan metode kuantitatif dengan penggujian hipotesis yang menggunakan model regresi dengan data sekunder. Dalam bagian metode penelitian ini disajikan model regresi yang digunakan untuk menguji hipotesis, variabel-variabel penelitian, dan prosedur pemilihan sampel beserta sumber data.

\section{Model Regresi}

Penelitian ini menggunakan model regresi yang mirip dengan model regresi dalam Liu (2014) yaitu sebagai berikut:

1. Model 1a dengan subsampel BUMN digunakan untuk menguji hipotesis la dan hipotesis $1 b$;
2. Model 1a dengan subsampel NON-BUMN digunakan untuk menguji hipotesis $2 \mathrm{a}$ dan hipotesis $2 b$;

3. Model 1b dengan sampel penuh (BUMN dan NON-BUMN) digunakan untuk menguji hipotesis $3 a$ dan hipotesis $3 b$.

$$
\begin{aligned}
& \text { PRICE }=\beta 0+\beta 1 \text { EPS }+\beta 2 \text { BVPS }+\beta 3 \text { SRA }+ \\
& \beta 4 \mathrm{DER}+\beta 5 \mathrm{SIZE}+\mathrm{e} \quad 1 \mathrm{a} \\
& \text { PRICE }=\beta 0+\beta 1 \text { EPS }+\beta 2 \text { EPSXBUMN }+ \\
& \beta 3 \text { BVPS }+\beta 4 \text { BVPSXBUMN }+ \\
& \beta 5 \mathrm{SRA}+\beta 6 \mathrm{DER}+\beta 7 \mathrm{SIZE}+\mathrm{e}
\end{aligned}
$$

Hasil regresi mendukung Hla jika $\beta_{1}$ dalam model 1a untuk subsampel BUMN adalah positif dan signifikan dan mendukung H1b jika $\beta_{2}$ dalam model 1a untuk subsampel BUMN adalah positif dan signifikan. Hasil regresi mendukung $\mathrm{H} 2 \mathrm{a}$ jika $\beta_{1}$ dalam model 1a untuk subsampel NONBUMN adalah positif dan signifikan dan mendukung $\mathrm{H} 2 \mathrm{~b}$ jika $\beta_{2}$ dalam model 1a untuk subsampel NON-BUMN adalah positif dan signifikan. Hasil regresi mendukung H3a jika $\beta_{2}$ dalam model 1b untuk sampel penuh (BUMN dan NON-BUMN) adalah positif dan signifikan dan mendukung H3b jika $\beta_{4}$ dalam model 1b untuk sampel penuh (BUMN dan NON-BUMN) adalah positif dan signifikan.

\section{Definisi Operasional dan Pengukuran Variabel}

Variabel dependen dalam penelitian ini adalah harga saham (yang digunakan dalam model 1a dan model 1b). Harga saham (PRICE) adalah harga saham penutupan perusahaan $\mathrm{j}$ pada tahun $\mathrm{t}$. Variabel independen untuk penelitian ini adalah laba per saham (earnings per share, EPS) dan nilai buku ekuitas per saham (book value per share, BVPS). EPS adalah laba bersih per saham perusahaan $\mathrm{j}$ pada tahun $\mathrm{t}$, sedangkan BVPS nilai buku ekuitas per saham dalam dalam laporan posisi keuangan (neraca) dibagi dengan jumlah saham untuk perusahaan $\mathrm{j}$ pada tahun t. Variabel interaksi EPSxBUMN dan BVPSxBUMN merupakan hasil perkalian EPS dan BVPS dengan variabel BUMN. Variabel BUMN ini merupakan dummy variable, yaitu diberi nilai 1 jika perusahaan adalah BUMN dan diberi nilai 0 jika perusahaan adalah NON-BUMN Variabel kontrol dalam penelitian ini adalah Sustainability Reporting Awards (SRA) 
yang merupakan dummy variable, yaitu diberi nilai 1 jika perusahaan merupakan penerima/ pemenang Sustainability Reporting Awards (SRA) dari The National Center for Sustainability Reporting (NCSR) dan diberi nilai 0 jika perusahaan adalah bukan pemenang SRA. SRA dimasukkan ke dalam model regresi karena hasil studi Sutopo et al. (2018) menunjukkan bahwa SRA berpengaruh pada relevansi nilai laporan keuangan.

\section{Teknik Pengumpulan Data}

BUMN dalam penelitian ini adalah BUMN yang go-public atau BUMN yang terdaftar di Bursa Efek Indonesia (BEI) karena penelitian ini menguji relevansi nilai informasi akuntansi yang memerlukan data harga saham. Sumber data daftar BUMN tersebut adalah website Kementerian BUMN (http://www.bumn.go.id/halaman/saham). Data variabel dependen harga saham (PRICE) dan data informasi dalam laporan keuangan yang meliputi laba per saham (earnings per share, EPS) dan nilai buku ekuitas per saham (book value per share, BVPS) diperoleh atau dihitung dari Fact Book untuk masing-masing tahun yang sesuai dengan kebutuhan. Data penerima/ pemenang Sustainability Reporting Awards (SRA) diperoleh dari website The National Center for Sustainability Reporting (NCSR). Data perusahaan-perusahaan BUMN diperoleh dari website Kementerian BUMN.

\section{Populasi dan Sampel}

Sampel penelitian ini meliputi 194 observasi panel unbalanced (yang terdiri dari 97 BUMN dan 97 NON-BUMN) dan 180 observasi panel balanced (yang terdiri dari 90 BUMN dan 90 NON-BUMN). Pemilihan sampel disajikan di Tabel 1.

Proses pemilihan sampel:

1. Mengidentifikasi perusahaanperusahaan BUMN berdasarkan daftar BUMN yang terdaftar di Bursa Efek Indonesia yang diambil dari website Kementerian BUMN;

2. Mengididentifikasi jenis industri dari masing-masing BUMN;

3. Menghitung jumlah BUMN untuk masing-masing industri dan untuk masingmasing tahun;
4. Memilih perusahaan-perusahaan NonBUMN untuk masing-masing industri dan untuk masing-masing tahun dengan jumlah yang sama.

5.. Perusahaan pembanding (Non-BUMN) dipilih berdasarkan Size perusahaan yang mendekati perusahaan BUMN.

\section{ANALISIS DAN PEMBAHASAN \\ Statistik Deskriptif}

Statistik deskriptif yang disajikan di Tabel 2 yang meliputi statistik deskriptif untuk sampel penuh (BUMN dan NON-BUMN), untuk subsampel perusahaan-perusahaan BUMN, dan untuk subsampel perusahaanperusahaan NON-BUMN. Nilai mean dari laba per saham (earnings per share, EPS) untuk subsample BUMN adalah lebih tinggi dibandingkan nilai-nilai yang sama untuk subsampel NON-BUMN, dan nilai mean dari harga saham (PRICE) untuk BUMN adalah juga lebih tinggi dibandingkan nilai yang sama untuk NON-BUMN. Berbeda dengan hasil tersebut, nilai mean dari nilai buku ekuitas per saham (book value per share, BVPS) untuk perusahaan perusahaan BUMN adalah lebih rendah dibandingkan nilai yang sama untuk perusahaan-perusahaan

Tabel 1.

Jumlah Observasi Perusahaan

BUMN dan NON-BUMN Tahun 2012-2016 sebagai Sampel - Data Panel Unbalanced

$(\mathrm{N}=194)$ dan Balanced $(\mathrm{N}=180)$

Tahun BUMN NON-BUMN Jumlah

Panel A: Observasi panel unbalanced total: 194

$\begin{array}{llll}2012 & 18 & 18 & 36 \\ 2013 & 19 & 19 & 38 \\ 2014 & 20 & 20 & 40 \\ 2015 & 20 & 20 & 40 \\ 2016 & 20 & 20 & 40 \\ 2012- & 97 & 97 & 194 \\ 2016 & & \end{array}$

Panel B: Observasi panel unbalanced total: 180

\begin{tabular}{cccc}
2012 & 18 & 18 & 36 \\
2013 & 18 & 18 & 36 \\
2014 & 18 & 18 & 36 \\
2015 & 18 & 18 & 36 \\
2016 & 18 & 18 & 36 \\
$2012-$ & 90 & 90 & 180 \\
2016 & 90 \\
\hline
\end{tabular}


NON-BUMN. Mean SRA untuk subsampel BUMN adalah 0.30 yang berarti bahwa jumlah perusahaan-penerima penerima SRA adalah 30 persen, sedangkan proporsi penerima SRA untuk subsampel NONBUMN hanya 0.06. Artinya, hanya 0.6 persen dari perusahaan-perusahaan NONBUMN adalah penerima SRA.

\section{ANALISIS DAN PEMBASAHAN}

Hasil regresi pengaruh EPS terhadap harga saham (PRICE) tanpa variabel kontrol disajikan di Tabel 3a, sedangkan hasil regresi pengaruh EPS terhadap harga saham (PRICE) dengan variabel kontrol disajikan di Tabel 3b. Keduanya menggunakan subsampel BUMN (N=97), subsampel NONBUMN (N=97), dan sampel penuh (BUMN dan NON-BUMN) sebanyak 194 observasi (dengan menggunakan data panel unbalanced). Nilai F untuk subsampel dan sampel penuh relatif tinggi dan signifikan pada level 1 persen, yang berarti bahwa secara bersama-sama EPS, BVPS, dan variabel kontrol berpengaruh pada harga saham.

Tabel 2a.

Statistik Deskriptif - Panel (Unbalanced) Observations

\begin{tabular}{lrrrr}
\hline \multicolumn{1}{c}{ Var } & \multicolumn{1}{c}{ Mean } & \multicolumn{1}{c}{ Max } & \multicolumn{1}{c}{ Min } & Std. Dev. \\
\cline { 1 - 3 } PANEL A: BUMN DAN NON-BUMN $(\mathrm{N}=194)$ & \\
PRICE & 3070.33 & 25000.00 & 50.00 & 4146.14 \\
EPS & 224.38 & 3322.00 & -490.00 & 414.79 \\
BVPS & 2002.13 & 25250.00 & 125.00 & 3701.89 \\
SRA & 0.20 & 1.00 & 0.00 & 0.40 \\
DER & 2.65 & 11.40 & 0.00 & 2.88 \\
SIZE & 9.86 & 13.85 & 6.40 & 1.80
\end{tabular}

PANEL B: BUMN (N=97)

\begin{tabular}{lrrrr} 
PRICE & 4027.03 & 16200.00 & 153.00 & 4142.44 \\
EPS & 304.11 & 3322.00 & -280.00 & 456.40 \\
BVPS & 1853.18 & 13712.12 & 185.79 & 2008.63 \\
SRA & 0.30 & 1.00 & 0.00 & 0.46 \\
DER & 2.74 & 11.40 & 0.00 & 2.78 \\
SIZE & 10.44 & 13.85 & 7.08 & 1.73 \\
PANEL C: NON-BUMN (N=97) & & \\
PRICE & 2113.62 & 25000.00 & 50.00 & 3943.41 \\
EPS & 144.66 & 1803.00 & -490.00 & 353.20 \\
BVPS & 2151.07 & 25250.00 & 125.00 & 4844.73 \\
SRA & 0.09 & 1.00 & 0.00 & 0.29 \\
DER & 2.56 & 10.98 & 0.00 & 2.98 \\
SIZE & 9.28 & 12.39 & 6.40 & 1.68 \\
\hline
\end{tabular}

Nilai R-squared dan Adjusted R-squared juga relatif tinggi yang menunjukkan bahwa EPS dan BVPS mempunyai pengaruh yang relatif besar pada harga saham.

Hasil regresi di Tabel 3a untuk subsampel BUMN, subsampel NON-BUMN, dan subsampel gabungan BUMN dan NONBUMN menunjukkan bahwa koefisien EPS adalah positif dan signifikan pada level 1 persen. Tabel $3 \mathrm{~b}$ dengan menggunakan variabel kontrol menunjukkan hasil regresi yang konsisten dengan hasil di Tabel 3a. Hasil ini menunjukkan bahwa EPS perusahaan-perusahaan BUMN, NON-BUMN, dan gabungan BUMN-NONBUMN mempunyai relevansi nilai. Hasil regresi di Tabel 3a dan Tabel 3b untuk sampel penuh (BUMN dan NON-BUMN) menunjukkan bahwa koefisien variabel interaksi EPSxBUMN adalah negatif tetapi tidak signifikan, Hasil ini menunjukkan bahwa relevansi nilai EPS perusahaanperusahaan BUMN tidak berbeda dengan relevansi nilai EPS perusahaan-perusahaan NON-BUMN.

Tabel 2B.

Statistik Deskriptif - Panel (balanced) Observations

\begin{tabular}{lrrrr}
\hline \multicolumn{1}{c}{ Var } & \multicolumn{1}{c}{ Mean } & \multicolumn{1}{c}{ Max } & \multicolumn{1}{c}{ Min } & Std. Dev. \\
\cline { 1 - 3 } \multicolumn{2}{l}{ PANEL A: BUMN DAN NON-BUMN $(\mathrm{N}=180)$} & \\
PRICE & 2901.48 & 16200.00 & 50.00 & 3545.96 \\
EPS & 218.46 & 3322.00 & -490.00 & 407.97 \\
BVPS & 2016.68 & 25250.00 & 125.00 & 3773.91 \\
SRA & 0.20 & 1.00 & 0.00 & 0.40 \\
DER & 2.75 & 11.40 & 0.00 & 2.95 \\
SIZE & 9.88 & 13.85 & 6.40 & 1.85
\end{tabular}

PANEL B: BUMN ( $\mathrm{N}=90)$

$\begin{array}{lrrrr}\text { PRICE } & 4234.06 & 16200.00 & 153.00 & 4223.15 \\ \text { EPS } & 323.45 & 3322.00 & -280.00 & 468.35 \\ \text { BVPS } & 1959.71 & 13712.12 & 185.79 & 2045.40 \\ \text { SRA } & 0.32 & 1.00 & 0.00 & 0.47 \\ \text { DER } & 2.83 & 11.40 & 0.00 & 2.85 \\ \text { SIZE } & 10.54 & 13.85 & 7.08 & 1.73\end{array}$

PANEL C: NON-BUMN (N=90)

\begin{tabular}{lrrrr} 
PRICE & 1568.91 & 14850.00 & 50.00 & 1965.35 \\
EPS & 113.47 & 1803.00 & -490.00 & 305.13 \\
BVPS & 2073.66 & 25250.00 & 125.00 & 4945.16 \\
SRA & 2.68 & 10.98 & 0.00 & 3.05 \\
DER & 0.08 & 1.00 & 0.00 & 0.27 \\
SIZE & 9.21 & 12.39 & 6.40 & 1.73 \\
\hline
\end{tabular}


Koefisien variabel kontrol SRA untuk subsampel BUMN adalah positif dan signifikan, yang berarti bahwa harga saham perusahaan-perusahaan BUMN yang mendapat SRA adalah lebih tinggi dibandingkan dengan harga saham perusahaan-perusahaan BUMN yang tidak mendapat SRA. Hasil ini mungkin disebabkan oleh jumlah perusahaan BUMN penerima SRA relatif lebih banyak (30\%) (Lihat Tabel 2a Panel B). Untuk perusahaanperusahaan NON-BUMN, harga saham penerima SRA tidak berbeda dengan harga saham non-penerima SRA. Hasil ini mungkin disebabkan oleh jumlah perusahaan NON-
BUMN penerima SRA relatif lebih sedikit (0.9\%) (Lihat Tabel 2a Panel C). Variabel kontrol DER dan SIZE baik untuk subsampel BUMN maupun untuk subsampel NONBUMN adalah tidak signifikan. Pendanaan utang (DER) dan ukuran perusahaan (SIZE) tidak berpengaruh terhadap harga saham.

Hasil regresi pengaruh BVPS terhadap harga saham (PRICE) tanpa variabel kontrol disajikan di Tabel 4a, sedangkan hasil regresi pengaruh BVPS terhadap harga saham (PRICE) dengan variabel kontrol disajikan di Tabel 4b. Keduanya menggunakan subsampel BUMN (N=97), subsampel NON-BUMN (N=97), dan sampel

Tabel 3a.

Hasil Regresi Pengaruh Laba Per Saham (EPS) terhadap Harga Saham (PRICE) Tanpa Variabel Kontrol - Panel (unbalanced) Observations

\begin{tabular}{|c|c|c|c|c|c|c|c|c|}
\hline \multirow{3}{*}{ Variable } & \multirow{2}{*}{\multicolumn{2}{|c|}{$\begin{array}{l}\text { BUMN } \\
N=97\end{array}$}} & \multirow{2}{*}{\multicolumn{2}{|c|}{$\begin{array}{c}\text { NON-BUMN } \\
\mathrm{N}=97\end{array}$}} & \multirow{2}{*}{\multicolumn{2}{|c|}{$\begin{array}{c}\text { BUMN \& NON- } \\
\text { BUMN } \\
\mathrm{N}=194\end{array}$}} & \multirow{2}{*}{\multicolumn{2}{|c|}{$\begin{array}{c}\text { BUMN \& NON- } \\
\text { BUMN } \\
\text { N }=194\end{array}$}} \\
\hline & & & & & & & & \\
\hline & Coef. & Prob. & Coef. & Prob. & Coef. & Prob. & Coef. & Prob. \\
\hline EPS & 2.23 & 0.00 & 2.54 & 0.00 & 2.23 & 0.00 & 3.73 & 0.00 \\
\hline EPSXBUMN & & & & & & & -0.10 & 0.25 \\
\hline $\mathrm{C}$ & 3348.77 & 0.00 & 1745.79 & 0.00 & 3348.77 & 0.00 & 2499.15 & 0.00 \\
\hline R-squared & 0.89 & & 0.90 & & 0.89 & & 0.90 & \\
\hline Adj. R-squared & 0.86 & & 0.88 & & 0.86 & & 0.88 & \\
\hline F-statistic & 30.64 & & 36.17 & & 30.64 & & 34.58 & \\
\hline Prob (F-statistic) & 0.00 & & 0.00 & & 0.00 & & 0.00 & \\
\hline Metode & Fixed & ects & Fixed & ects & Fixed e & ects & Fixed $\epsilon$ & ects \\
\hline
\end{tabular}

Tabel 3b.

Hasil Regresi Pengaruh Laba Per Saham (EPS) terhadap Harga Saham (PRICE) Dengan Variabel Kontrol - Panel (unbalanced) Observations

\begin{tabular}{|c|c|c|c|c|c|c|c|c|}
\hline \multirow{3}{*}{ Variable } & \multirow{2}{*}{\multicolumn{2}{|c|}{$\begin{array}{l}\text { BUMN } \\
N=97\end{array}$}} & \multirow{2}{*}{\multicolumn{2}{|c|}{$\begin{array}{c}\text { NON-BUMN } \\
\qquad \begin{array}{c}\mathrm{N}=97\end{array}\end{array}$}} & \multirow{2}{*}{\multicolumn{2}{|c|}{$\begin{array}{c}\text { BUMN \& NON- } \\
\text { BUMN } \\
\text { N }=194\end{array}$}} & \multirow{2}{*}{\multicolumn{2}{|c|}{$\begin{array}{c}\text { BUMN \& NON- } \\
\text { BUMN } \\
\mathrm{N}=194\end{array}$}} \\
\hline & & & & & & & & \\
\hline & Coef. & Prob. & Coef. & Prob. & Coef. & Prob. & Coef. & Prob. \\
\hline EPS & 2.07 & 0.00 & 2.44 & 0.00 & 2.34 & 0.00 & 3.78 & 0.00 \\
\hline EPSXBUMN & & & & & & & -0.10 & 0.25 \\
\hline SRA & 1765.80 & 0.00 & -703.05 & 0.30 & 723.88 & 0.10 & 722.86 & 0.10 \\
\hline DER & -367.84 & 0.15 & -157.37 & 0.46 & -203.16 & 0.22 & -169.67 & 0.31 \\
\hline SIZE & 413.55 & 0.44 & 81.43 & 0.91 & 442.65 & 0.29 & 540.23 & 0.20 \\
\hline $\mathrm{C}$ & -438.08 & 0.94 & 1473.05 & 0.82 & -1423.08 & 0.74 & -2524.91 & 0.56 \\
\hline R-squared & 0.89 & & 0.91 & & 0.91 & & 0.91 & \\
\hline Adj. R-squared & 0.86 & & 0.88 & & 0.88 & & 0.88 & \\
\hline F-statistic & 30.64 & & 30.82 & & 33.88 & & 33.21 & \\
\hline Prob (F-statistic) & 0.00 & & 0.00 & & 0.00 & & 0.00 & \\
\hline Metode & Fixed e & ects & Fixed e & ects & Fixed e & cts & Fixed ef & cts \\
\hline
\end{tabular}


penuh (BUMN dan NON-BUMN) sebanyak 194 observasi (dengan menggunakan data panel unbalanced). Nilai F untuk subsampel dan sampel penuh relatif tinggi dan signifikan pada level 1 persen, yang berarti bahwa secara bersama-sama BVPS dan variabel kontrol berpengaruh pada harga saham. Nilai R-squared dan Adjusted R-squared juga relatif tinggi yang menunjukkan bahwa BVPS mempunyai pengaruh yang relatif besar pada harga saham.

Hasil regresi di Tabel $4 \mathrm{a}$ untuk subsampel BUMN, subsampel NON-BUMN, dan subsampel gabungan BUMN dan NON-
BUMN menunjukkan bahwa koefisien BVPS adalah positif dan signifikan pada level 1 persen. Tabel $4 \mathrm{~b}$ dengan menggunakan variabel kontrol menunjukkan hasil regresi yang konsisten dengan hasil di Tabel 4a. Hasil ini menunjukkan bahwa BVPS perusahaan-perusahaan BUMN, NON-BUMN, dan gabungan BUMN-NONBUMN mempunyai relevansi nilai. Hasil regresi di Tabel 4 a dan Tabel 4b untuk sampel penuh (BUMN dan NON-BUMN) menunjukkan bahwa koefisien variabel interaksi BVPSXBUMN adalah negatif tetapi tidak signifikan, Hasil ini menunjukkan bahwa relevansi nilai BVPS

Tabel 4a.

Hasil Regresi Pengaruh Nilai Buku Per Saham (BVPS) terhadap Harga Saham (PRICE) Tanpa Variabel Kontrol - Panel (unbalanced) Observations

\begin{tabular}{|c|c|c|c|c|c|c|c|c|}
\hline \multirow[t]{2}{*}{ Variable } & \multicolumn{2}{|c|}{$\begin{array}{l}\text { BUMN } \\
\mathrm{N}=97\end{array}$} & \multicolumn{2}{|c|}{$\begin{array}{c}\text { NON-BUMN } \\
\qquad \mathrm{N}=97\end{array}$} & \multicolumn{2}{|c|}{$\begin{array}{c}\text { BUMN \& NON- } \\
\text { BUMN } \\
\text { N = } 194\end{array}$} & \multicolumn{2}{|c|}{$\begin{array}{c}\text { BUMN \& NON- } \\
\text { BUMN } \\
\text { N = } 194\end{array}$} \\
\hline & Coef. & Prob. & Coef. & Prob. & Coef. & Prob. & Coef. & Prob. \\
\hline BVPS & 0.50 & 0.00 & 0.38 & 0.03 & 0.46 & 0.00 & -0.03 & 0.94 \\
\hline BVPSXBUMN & & & 1285.78 & 0.00 & & & 0.03 & 0.20 \\
\hline $\mathrm{C}$ & 3104.78 & 0.00 & & & 2141.15 & 0.00 & 2279.78 & 0.00 \\
\hline R-squared & 0.89 & & 0.89 & & 0.89 & & 0.90 & \\
\hline $\begin{array}{l}\text { Adjusted R- } \\
\text { squared }\end{array}$ & 0.86 & & 0.86 & & 0.87 & & 0.87 & \\
\hline F-statistic & 30.21 & & 30.22 & & 32.29 & & 31.67 & \\
\hline Prob(F-statistic) & 0.00 & & 0.00 & & 0.00 & & 0.00 & \\
\hline Metode & Fixed e & fects & Fixed e & fects & Fixed e & fects & Fixed e & ffects \\
\hline
\end{tabular}

Tabel $4 b$.

Hasil Regresi Pengaruh Nilai Buku Per Saham (BVPS) terhadap Harga Saham (PRICE) Dengan Variabel Kontrol - Panel (unbalanced) Observations

\begin{tabular}{|c|c|c|c|c|c|c|c|c|}
\hline \multirow[t]{2}{*}{ Variable } & \multicolumn{2}{|c|}{$\begin{array}{l}\text { BUMN } \\
\mathrm{N}=97\end{array}$} & \multicolumn{2}{|c|}{$\begin{array}{c}\text { NON-BUMN } \\
\qquad \begin{array}{l}\mathrm{N}=97\end{array}\end{array}$} & \multicolumn{2}{|c|}{$\begin{array}{c}\text { BUMN \& NON- } \\
\text { BUMN } \\
\text { N = 194 }\end{array}$} & \multicolumn{2}{|c|}{$\begin{array}{c}\text { BUMN \& NON- } \\
\text { BUMN } \\
\text { N = } 194\end{array}$} \\
\hline & Coef. & Prob. & Coef. & Prob. & Coef. & Prob. & Coef. & Prob. \\
\hline BVPS & 2.07 & 0.00 & 2.44 & 0.00 & 0.43833 & 0 & -0.01 & 0.99 \\
\hline BVPSXBUMN & & & & & & & 0.03 & 0.25 \\
\hline SRA & 1765.80 & 0.00 & -703.05 & 0.30 & 797.643 & 0.0861 & 772.01 & 0.10 \\
\hline DER & -367.84 & 0.15 & -157.37 & 0.46 & -168.82 & 0.339 & -161.05 & 0.36 \\
\hline SIZE & 413.55 & 0.44 & 81.43 & 0.91 & -123.51 & 0.7727 & -158.18 & 0.71 \\
\hline $\mathrm{C}$ & -438.08 & 0.94 & 1473.05 & 0.82 & 3702.26 & 0.3902 & 4150.10 & 0.34 \\
\hline R-squared & 0.91 & & 0.91 & & 0.20 & & 0.90 & \\
\hline $\begin{array}{l}\text { Adjusted R- } \\
\text { squared }\end{array}$ & 0.88 & & 0.88 & & 0.19 & & 0.87 & \\
\hline F-statistic & 31.43 & & 30.82 & & 11.99 & & 29.89 & \\
\hline Prob(F-statistic) & 0.00 & & 0.00 & & 0.00 & & 0.00 & \\
\hline Metode & Fixed e & fects & Fixed e & fects & Fixed & ffects & Fixed & fects \\
\hline
\end{tabular}


perusahaan-perusahaan BUMN tidak berbeda dengan relevansi nilai BVPS perusahaan-perusahaan NON-BUMN.

Analisis tambahan dilakukan dengan menggunakan subsampel BUMN ( $\mathrm{N}=90)$, subsampel NON-BUMN (N=90), dan sampel penuh (BUMN dan NON-BUMN) sebanyak 180 observasi (dengan menggunakan data panel balanced). Secara kualitatif, hasil regresi adalah tidak berbeda dengan hasil di Tabel 3a, Tabel 3b, Tabel 4a, dan Tabel 4b. Tabel hasil regresi dengan balanced observations ini tidak disajikan agar hasil utama bisa ditonjolkan.

Secara umum, temuan penelitian ini menunjukkan bahwa relevansi nilai informasi laporan keuangan (EPS dan BVPS) untuk perusahaan-perusahaan BUMN adalah tidak berbeda jika dibandingkan dengan relevansi nilai informasi laporan keuangan untuk perusahaan-perusahaan NON-BUMN. Relevansi nilai informasi laporan merupakan merupakan suatu proksi kualitas informasi tersebut. Perusahaan-perusahaan BUMN menghasilkan laba per saham (EPS) yang relatif lebih tinggi dibandingkan dengan NON-BUMN tetapi BUMN mempunyai nilai buku ekuitas per saham (BVPS) yang relatif lebih rendah dibandingkan dengan NON-BUMN. Di samping itu, harga saham BUMN adalah juga lebih tinggi dibandingkan dengan harga saham NONBUMN. Hasil ini diikuti dengan kualitas informasi laporan keuangan (relevansi nilai laporan keuangan) perusahaan-perusahaan BUMN yang tidak berbeda jika dibandingkan dengan kualitas informasi laporan keuangan perusahaan-perusahaan NON-BUMN. Kualitas informasi laporan keuangan ini bisa disebabkan komponen akrual dari laba yang tinggi. Akrual sering digunakan untuk mengukur kualitas informasi laba.

Menurut UU No. 19 Tahun 2003 tentang BUMN, perusahaan BUMN Persero mempunyai tujuan utama mengejar keuntungan. BUMN Persero Terbuka, yang menjadi fokus penelitian ini, harus bersaing dengan perusahaan NON-BUMN agar mampu mencapai tujuan utama mengejar keuntungan. Salah satu aspek untuk membandingkan antara BUMN dan NON-BUMN adalah dengan membandingkan relevansi nilai informasi dalam laporan keuangan.
Temuan penelitian ini ternyata mengindikasi bahwa perusahaan-perusahaan BUMN belum dapat mengungguli (tidak berbeda dibandingkan dengan) perusahaanperusahaan NON-BUMN dalam hal kualitas informasi akuntansi yang disajikan dalam laporan keuangan khususnya informasi EPS dan BVPS. Hasil penelitian ini bahkan menunjukkan bahwa EPS dan BVPS perusahaan-perusahaan BUMN tidak mempunyai relevansi nilai. Temuan ini dengan mempertimbangkan segala keterbatasannya, dapat dijadikan pertimbangan berbagai pihak yang berkepentingan dengan BUMN (pemangku kepentingan BUMN) dalam membuat keputusan-keputusan masingmasing pihak tersebut.

Hasil penelitian mendukung hipotesis relevansi nilai BUMN dan relevansi nilai NON-BUMN, tetapi relevansi nilai informasi akuntansi BUMN tidak berbeda dengan relevansi nilai informasi akuntansi NON-BUMN. Hal ini mungkin disebabkan bahwa perusahaan-perusahaan BUMN relatif belum lama dalam melaksanakan penawaran saham di Bursa Efek.

Studi ini memberi kontribusi dengan menyediakan hasil empiris yang menunjukkan bahwa ternyata relevansi nilai informasi akuntansi BUMN tidak berbeda (belum bisa menggungguli) relevansi nilai informasi akuntansi NON-BUMN. Hasil ini bermakna bahwa BUMN meskipun sudah menhasilkan informasi yang berkualitas tetapi belum mengungguli NON-BUMN.

\section{SIMPULAN DAN IMPLIKASI \\ Simpulan}

Penelitian ini menguji relevansi nilai informasi dalam laporan keuangan yang meliputi laba per saham (earnings per share, EPS) dan nilai buku ekuitas per saham (book value per share, BVPS) perusahaan-perusahaan badan usaha milik negara (BUMN) dan perusahaan-perusahaan non badan usaha milik negara (NON-BUMN) yang terdaftar di Bursa Efek Indonesia. Relevansi nilai ini ditunjukkan oleh pengaruh EPS dan BVPS terhadap harga saham (PRICE). Selanjutnya, studi ini membandingkan antara relevansi nilai informasi dalam laporan keuangan perusahaan-perusahaan BUMN dengan relevansi nilai informasi dalam laporan keu- 
angan perusahaan-perusahaan NON-BUMN. Hasil penelitian ini menunjukkan bahwa untuk perusahaan-perusahaan BUMN, baik EPS maupun BVPS perusahaan-perusahaan BUMN tidak berpengaruh pada harga saham. Penelitian ini menemukan bahwa untuk perusahaan-perusahaan NON-BUMN, EPS berpengaruh positif terhadap harga saham, sedangakan BVPS berpengaruh terhadap harga saham.

Temuan penelitian ini mendukung hipotesis relevansi nilai informasi akuntansi BUMN dan NON-BUMN. Dalam analisis regresi dilakukan analisis EPS dan BVPS secara terpisah karena keduanya berkorelasi positif sangat tinggi. Ketika keduanya digabung, maka keduanya menjadi tidak signifikan meskipun R-square tinggi. Korelasi yang tinggi antar variabel independen berakibat demikian. Selanjutnya, studi ini menemukan bahwa antara relevansi nilai informasi dalam laporan keuangan perusahaan-perusahaan BUMN adalah tidak berbeda dibandingkan dengan relevansi nilai informasi dalam laporan keuangan perusahaan-perusahaan NONBUMN.

\section{Implikasi}

Implikasi dari hasil penelitian ini adalah bahwa perusahaan-perusahaan BUMN perlu meningkatkan relevansi nilai informasi dalam laporan keuangan, yang dalam hal ini meliputi EPS dan BVPS agar mampu bersaing dengan perusahaan-perusahaan NONBUMN. Regulasi tentang pelaporan keuangan perusahaan-perusahaan BUMN perlu mempertimbangkan peningkatan kualitas informasi laporan keuangan dalam rangka bersaing dengan perusahaan-perusahaan non-BUMN yang terdaftar di Bursa Efek Indonesia. Investor perlu mempertimbangkan kualitas informasi laporan keuangan EPS dan BVPS dalam penilaian saham dan pengambilan keputusan investasi.

\section{KETERBATASAN DAN SARAN Keterbatasan}

Dalam menginterpretasi hasil penelitian ini, perlu diperhatikan keterbatasanketerbatasan penelitian ini. Pemilihan perusahaan-perusahaan NON-BUMN sebagai pembanding BUMN mengandung unsur subyektifitas yang dapat berdampak pada simpulan yang bias. Meskipun demikian, pemilihan perusahaan-perusahaan NONBUMN sudah dilakukan dengan pertimbangan-pertimbangan tertentu untuk meminimumkan bias hasil. Pemilihan NONBUMN tersebut telah mempertimbangkan sektor yang sama dan ukuran perusahaan yang mendekati ukuran perusahaan BUMN.

\section{Saran}

Penelitian berikutnya dapat mempertimbangkan kriteria pemilihan sampel yang lain seperti kelompok industri jika jumlah observasi yang memadai sudah tersedia. Pengujian relevansi nilai sebagai suatu proksi kualitas informasi akuntansi dapat dilakukan dengan membandingkan dengan proksi kualitas informasi akuntansi yang lain seperti manajemen laba dan/atau persistensi laba.

\section{DAFTAR PUSTAKA}

Agustina, W., Yuniarta, G. A., Ak, S., \& Sinarwati, N. K. (2015). Pengaruh intelectual capital, corporate social responsibility dan good corporate governance terhadap kinerja keuangan (studi kasus pada perusahaan bumn yang terdaftar di bursa efek indonesia pada tahun 2011-2013). JIMAT (Jurnal Ilmiah Mahasiswa Akuntansi) Undiksha, 3(1): 1 $-15$.

Ariyadi, F., \& Wiratno, A. (2018). Relevansi Nilai Dan Subjektifitas Dari Other Comprehensive Income Pada Perusahaan Industri Jasa Keuangan. Jurnal Ilmiah Professional Indonesia, 2(1), 59-74.

Aryati, T., \& Wibowo, N. N. (2017). Pengaruh Relevansi Nilai Informasi Other Comprehensive Income Dan Net Income Terhadap Return Saham. Media Riset Akuntansi, Auditing \& Informasi, 17(1), 53-66.

Asyikin, J., \& Tanu, V. S. (2011). Analisis perbandingan kinerja keuangan antara perusahaan farmasi milik pemerintah (BUMN) dengan perusahaan farmasi swasta yang terdaftar di Bursa Efek Indonesia. Jurnal Ilmiah Bisnis dan Keuangan, 1(1): 36-48.

Avianti, I. (2017). Privatisasi BUMN dan Penegakan Good Corporate Governance dan Kinerja BUMN. Kinerja, 10(1), 5765.

Cahyaningrum, D. (2009). Hambatan Implementasi Tata Kelola Perusahaan Yang Baik (Good Corporate Governance) 
Pada Badan Usaha Milik Negara (Bumn) Yang Berbentuk Persero. Kajian, 14(3), 463-487.

Chasanah, C., \& Kiswara, E. (2017). Pengaruh Laba Per Lembar Saham, Nilai Buku Per Lembar Saham, Dan Transaksi Abnormal Pihak Berelasi Terhadap Relevansi Nilai Dengan Mekanisme Tata Kelola Perusahaan Sebagai Variabel Moderasi. Diponegoro Journal of Accounting, 6(3), 16-25.

Ciptaningsih, T. (2013). Uji Pengaruh Modal Intelektual terhadap Kinerja Keuangan BUMN yang Go Public di Indonesia. Journal of Technology Management, 12(3): 330-348.

Dechow, P. M., \& Ge, W. (2006). The persistence of earnings and cash flows and the role of special items: Implications for the accrual anomaly. Review of Accounting studies, 11(2-3), 253-296.

Fitriani, A. 2013. Pengaruh Kinerja Lingkungan Dan Biaya Lingkungan Terhadap Kinerja Keuangan Pada BUMN. Jurnal Ilmu Manajemen, 1(1): 137-147.

IAI. 2016. Kerangka Dasar Penyusunan dan Penyajian Laporan Keuangan (KDPPLK). Ikatan Akuntan Indonesia (IAI). Jakarta: 2016.

Istighfarin, D., \& Wirawati, N. G. P. (2015). Pengaruh Good Corporate Governance Terhadap Profitabilitas Pada Badan Usaha Milik Negara (BUMN). E-Jurnal Akuntansi, 564-581.

Kaligis, Y. W. (2013). Analisis Tingkat Kesehatan Bank Dengan Menggunakan Metode Camel Pada Industri Perbankan Bumn Yang Terdaftar Di Bursa Efek Indonesia. Jurnal EMBA: Jurnal Riset Ekonomi, Manajemen, Bisnis dan Akuntansi, 1(3): 263-272.

Kusumadewi, T. A. (2013). Kemitraan BUMN dengan UMKM sebagai Bentuk Corporate Social Responsibility (CSR)(Studi Kemitraan PT. TELKOM Kandatel Malang dengan UMKM Olahan Apel di Kota Batu). Jurnal Administrasi Publik, 1(5), 953-961.

Lebelaha, D. L. (2016). Pengaruh price earnings ratio, debt to equity ratio dan dividend payout ratio terhadap nilai perusahaan BUMN yang terdaftar di Bursa Efek Indonesia periode 20112014. Jurnal Berkala Ilmiah Efisiensi, 16(2): 376-386.

Linda \& Ningsih, E. S. (2012). Relevansi Nilai Laba Akuntansi pada Aksi Stock split: Pendekatan Model Harga Dan Return. In Conference in Business, Accounting, And Management (CBAM), 1(2): 517526.
Liu, C., Gould, G., \& Burgan, B. (2014). Value -relevance of financial statements: Evidence from A-and B-share markets in China. International Journal of Managerial Finance, 10(3), 332-367.

Marina, A., Wahjono, S. I., \& Fahmi, E. M. (2013). Bank BUMN Syariah Indonesia yang Kuat Perlu Segera Didirikan untuk Menyambut ASEAN Community 2015. In Seminar Nasional Universitas Muhammadiyah Sidoarjo.

Rahman, A. F. (2017). Masalah Keagenan Aliran Kas Bebas, Manajemen Laba dan Relevansi Nilai Informasi Akuntansi. EKUITAS (Jurnal Ekonomi dan Keuangan), 15(2), 232-246.

Rahmawati, N. D., Saerang, I. S., \& Van Rate, P. (2014). Kinerja Keuangan Pengaruhnya Terhadap Kebijakan Dividen Pada Perusahaan Bumn Di Bursa Efek Indonesia. Jurnal EMBA: Jurnal Riset Ekonomi, Manajemen, Bisnis dan Akuntansi, 2(2): 1306-1317.

Romadhoni, R., \& Purwanti, D. (2017). Pengaruh Adopsi IAS Dan IFRS terhadap Relevansi Nilai Laporan Keuangan (Studi Empiris Pada Perusahaan Jasa Keuangan yang Tercatat di Bei Tahun 2008-2013). Jurnal Substansi 1 (1): 25-60.

Scott, W. R. (2015). Financial Accounting Theory. 7 ed. Ontario: Pearson Canada Inc.

Suharli, M., \& Nurlaelah, N. (2008). Konsentrasi Auditor dan Penetapan Fee $\mathrm{Au}-$ dit: Investigasi Pada BUMN. Jurnal Akuntansi dan Auditing Indonesia, 12 (2): 124-140.

Sutopo, B., Kot, S., Adiati, A. K., \& Ardila, L. N. (2018). Sustainability Reporting and Value Relevance of Financial Statements. Sustainability, 10(3), 678: 1-14.

Thrisye, R. Y., \& Simu, N. (2013). Analisis pengaruh rasio keuangan terhadap return saham BUMN sektor pertambangan periode 2007-2010. Jurnal Ilmiah Akuntansi dan Bisnis, 8(2): 7581.

Umbara, D., Oemar, A., \& Pranaditya, A. (2017). Pengaruh Penerapan Psak Konvergensi IFRS Terhadap Relevansi Nilai Informasi Akuntansi Dengan DNI Sebagai Variabel Moderating Pada Perusahaan Manufaktur Di Bei Periode 2007-2009 dan 2014-2016. Journal of Accounting, 3(3): 1-18.

Undang-Undang Republik Indonesia Nomor 19 Tahun 2003 Tentang Badan Usaha Milik Negara.

Yudiman, A. T., \& Ahmar, N. (2017). Relevansi Nilai Net Income, Comprehen- 
Why does the recently adopted performance measurement system in Indonesia local government not work well? (Fahlevi, Nuzulia, dan Basri)

sive Income dan Other Comprehen-

ufaktur. Jurnal Ilmiah Professional sive Income Pada Perusahaan ManIndonesia, 1(1), 1-16. 